\title{
Del amor personal humano al divino Un estudio desde la antropología trascendental de L. Polo
}

\author{
JUAN FERNANDO SELLÉS \\ Universidad de Navarra (España) \\ jfselles@unav.es
}

\begin{abstract}
Resumen
En este trabajo se estudia del amor personal humano y del amor personal divino desde la antropología trascendental de Leonardo Polo. Se indica que el amor personal humano está abierto naturalmente al mundo, a los demás, al propio hombre y, en especial, a Dios; que es creciente y que puede ser elevado. El amor personal divino es pluripersonal y está abierto al humano en su creación, elevación y glorificación.
\end{abstract}

Palabras clave: amor personal, humano y divino, antropología trascendental, L. Polo.

\section{Personal human love to divine A study from transcendental anthropology of $\mathrm{L}$. Polo}

\begin{abstract}
In this work we study the human personal love and the divine personal love according the transcendental anthropology of Leonardo Polo. We sustain that the buman personal love is naturally open to the world, to others, to the self, and over all to God; that it is growing and susceptible of be elevated by God. The divine personal love is pluripersonal and is open to the man in bis creation, elevation and glorification.
\end{abstract}

Key words: personal love, human and divine, transcendental anthropology, L. Polo.

Doctor en Filosofía por la Universidad de Navarra. Profesor titular de Antropología Filosófica de la misma universidad. Entre sus abundantes publicaciones se cuentan los libros Razón teórica y razón práctica según Tomás de Aquino (1999); Conocer y amar. Estudio de los objetos y operaciones del entendimiento y de la voluntad según Tomás de Aquino (2000); Los hábitos adquiridos. Las virtudes de la inteligencia y de la voluntad según Tomás de Aquino (2001); Propuestas antropológicas del siglo XX (2004); Antropologia para inconformes. Una antropologia abierta al futuro (2006); Los bábitos intelectuales según Tomás de Aquino (2008). 


\section{Planteamiento}

El tema del amor íntimo es uno de los superiores a los que se ha enfrentado la atención de los filósofos, literatos, humanistas de todos los tiempos, pero es también una realidad de las que más pesan en la vida de todos los hombres, pues sobre ella bascula la felicidad. Para abordarlo previamente hay que indicar que por 'amor personal' no se entiende aquí cualquier tipo de amor humano, máxime si se confunde con el placer sexual (como pensaron Marcuse o Fromm). Tampoco se trata del querer de la voluntad (parecer propio de Blondel, Nédoncelle, Lacroix, Pieper, Zubiri, Wilhelmsen, Mouroux, J.-L. Marion, M.D. Philippe, J.J. PérezSoba, etc.), o de visiones globalizantes de él, que lo atribuyen a las diversas dimensiones humanas sensibles y espirituales (como hicieron G. Thibon o C. S. Lewis). En efecto, todos esos 'amores' son de la persona, pero no la persona, es decir, radican en diversas facultades o dimensiones de la persona, pero no en su intimidad. En cambio, el 'amor personal' que aquí se indaga describe a la persona entendida como acto de ser personal, y tal amor queda referido a personas. Dada su altura, se comprende que por tal amor una persona esté dispuesta a entregar su vida y todas sus facultades, y que ésta no se comprenda separada de la persona a la que ama.

En efecto, cuando se ama, se ama a una persona, pues el 'amor personal' no es respecto de cosas (como postuló, por ejemplo, Laín Entralgo), sino de personas. Esto, que de ordinario parece obvio y que, por lo mismo, no es suficientemente considerado, tiene su trascendencia, porque si el hombre conoce a otros hombres y no los ama, seguramente será porque los conoce con su razón u otras dimensiones que tiene y que no son él mismo como ser cognoscente. A la par, si advierte a Dios y no lo ama personalmente, será porque está ejerciendo un conocer que no es personal, es decir, antropológico o íntimo, sino inferior (metafísico, racional o sensible). De otro modo: si no lo ama y lo conoce, es porque ejerce el hábito de los primeros principios y lo advierte como origen, como fundamento, pero no como persona, o lo piensa como una idea de la razón; o lo ve como una realidad sensible. En cambio, si lo conoce como 'persona', es porque lo está conociendo con el conocer personal que él es y, consecuentemente, lo ama personalmente, es decir, con el amor personal que es.

El amor es una perfección pura de índole personal que es característica del corazón humano. No se trata de una dimensión que el hombre tenga, sino una realidad de su ser. Por eso el amor no es un sentimiento (como han pensado, por ejemplo, Th. Haecker, D. von Hildebrand, H. Arendt, A. Soble, etc.), o un estado (como han postulado, 
por ejemplo, Laín Entralgo, Julián Marías, etc.). Es, más bien, una realidad que el hombre originariamente es, aunque inicialmente no sea consciente de ella, pues si no fuera esa realidad desde el origen, no podría manifestarla con el paso del tiempo en las diversas potencias humanas, las cuales son progresivamente activadas por ella. Es una dimensión radical, porque es lo superior, y esto no surge de lo inferior: lo más activo no nace de lo potencial, sino a la inversa. A esta radicalidad humana se la puede designar como 'trascendental personal', la cual está nativamente vinculada a los otros trascendentales personales humanos.

Otra cuestión es si entre el amor personal humano y el divino cabe mediación. La respuesta es afirmativa. Puede caber mediación, pero no necesariamente, porque sólo el amor divino es el tema suficiente del amor personal humano. Se podría pensar en una persona angélica o humana entre Dios y el amante humano, y postular que se le podría amar a ella y no al ser divino. Pero esto no es posible, pues sostenerlo es no ver que tal persona es mediador de Dios. Si a los demás se les ama como son, no cabe más que amarles por Dios, porque cada una de ellas es una relación distinta a Dios. En efecto, es él quien las ha creado tal como son, distintas en cada caso, y esa distinción remite en cada una de ellas de un modo distinto a Dios. Por tanto, conociendo a cada cual como distinto, conocemos en cada caso un aspecto divino distinto. Por eso, en rigor, no es correcto sostener que cada persona creada sea un 'fin en sí, como pensaba Kant, pues las personas son de Dios y referidas a él, no 'de sí' y 'para sí, o 'de otras personas' y 'para ellas'.

\section{La apertura amorosa al mundo}

El amor personal humano es coexistente con la libertad y con el conocer personales. Como la libertad y el conocer personales están abiertos a la realidad sin restricción, también el amor lo está. Pero si el amor quiere las cosas no personales, las quiere por las personales, en rigor, por Dios. Así como el tema propio del conocer personal son las personas, así lo es la referencia del amar personal: «el hombre puede amar a las cosas en sí, pero no por sí; el motivo del amor personal está absolutizado. De este modo, con el amor el hombre cala la hondura real, la estrecha conexión de la cosa con su Causa, fuera de la cual la realidad creada no cabe. Precisamente por eso, un amor desordenado no es la mera limitación a un dato, sino una subversión del ordo amoris» (Polo, 1996a: 229). Estamos abiertos a querer al mundo, pero no lo podemos querer por sí, porque el mundo no puede responde a nuestro amor personal: ni lo acepta ni nos da su amor, puesto que carece de él. Por eso 
no podría existir un hombre solo en el mundo, porque el hombre es amor, y el amor personal exige correspondencia.

«Una relación persona-bien exclusiva o no respaldada por la persona vendría a ser un egoísmo trascendental... Cuando se trata de la persona, el mal radical... es la ausencia definitiva de réplica... El hombre se complace ante los trascendentales metafísicos. Por ejemplo, la belleza del mar, o una puesta de sol. Con todo, la persona exige más, por ser además. En este orden, el hombre tiene derecho a esperar» (Polo, 1999: 166-167) amor, es decir, a que se le ame. Sin respuesta personal definitiva, carecería de sentido el amor personal. La correspondencia del mundo con la persona humana consagra esa ausencia de respuesta, puesto que el mundo no es persona y no ama. De manera que para que el mundo tenga sentido para el amor personal humano hay que verlo como un don, un regalo divino (obviamente no es un regalo humano) para la persona humana; y viceversa: lo que el hombre añade al mundo con su trabajo hay que verlo como un regalo ofrecido a quien lo pueda aceptar amorosamente.

La persona humana no se conforma con el bien, porque la persona no se reduce a su voluntad. Requiere amor porque es amor. «El amor dirigido a una cosa es natural porque se debe a que es buena. Pero en el orden de la persona el trascendental es el amar, y no tanto el bien. El bien es un trascendental metafísico. Según esto, sostener que Dios es el sumo bien es completamente legítimo, pero no es suficiente sin su radicación en el ser personal. Asimismo, la intelección humana es trascendental si la verdad se contempla como persona. Por eso, el conocimiento operativo es intencionalmente verdadero sin llegar a la verdad trascendental; al conmensurarse con el objeto, remite intencionalmente a la cosa, pero no a la persona» (Polo, 1999: 166). Las cosas del mundo, y éste mismo, cobran sentido de don amoroso cuando son otorgadas por un amor personal, y cuando son aceptadas por otro amor personal.

Las cosas intramundanas se pueden conocer sensible y racionalmente. Con la razón tales cosas se pueden conocer, a su vez, de varios modos, según su rendimiento técnico, o según su modo de ser: a lo primero se dedican más las ciencias positivas; a lo segundo, sobre todo, la ciencia clásicamente considerada, es decir, el saber acerca de los principios o causas. Superior a esos modos de conocer racional es el 'intelectual', el cual conoce el fundamento del universo físico; es el modo de conocer propio de la metafísica. Pero ninguno de esos conocimientos ve al mundo como don. Para ello se requiere aceptarlo personalmente y ofrecerlo a personas; se requiere, por tanto, del conocer personal vinculado al amar personal: «el saber puede ser aplicado; la ciencia tiene 
un aprovechamiento técnico; pero ese aprovechamiento, a su vez, reclama como rendimiento una nueva aptitud intelectual y un mejor amar. Sin ello, ese mundo técnico, que ya es humano porque está hecho por el hombre, se vuelve inhumano» (Polo, 1996b: 116).

El mundo conocido según los diversos niveles de conocimiento humano es el mismo, pero de él no se conoce lo mismo en cada uno de ellos. La distinción entre ellos es jerárquica, es decir, un nivel es superior al otro y conoce del mundo lo que el nivel inferior no podía conocer. Conocerlo vinculado al amor personal implica ejercer el nivel cognoscitivo superior, porque no se conoce el amor sin conocer la realidad personal, que es la superior existente (tanto creada como increada). «En suma, las criaturas espirituales son verdaderas en cuanto que en ellas el trascendental 'verdad' está radicado en el acto de ser, es decir, en el acto de conocer entendido trascendentalmente. Y de modo similar, el bien es precedido por el amar. Con otras palabras, estas criaturas son verdaderas por dos motivos: en cuanto que conocen y en cuanto que en ellas el conocimiento es acto de ser. En cambio, aquella criatura que no conoce, es verdadera sólo en un sentido: en cuanto que es conocida, es decir, en cuanto que existen las otras» (Polo, 1999: 72). El mundo es de este segundo estilo, pero cuando en vez de vincularlo al deseo o a la voluntad se vincula a la realidad oferente y aceptante del amor personal su bien se trueca en don. En la radicalidad de la persona están el amar y el conocer personales; no el conocer racional y sensible ni el deseo sensible y el querer de la voluntad. Si median el conocer y el amar personales, el mundo se conoce como don, no meramente como bien, ya sea éste útil, deleitable u honesto; es decir, se considera de un modo más profundo - por personal- que lo han considerado diversas vertientes de la filosofía precedentes.

\section{Amor de sí positivo y negativo}

Además de amar el mundo, una persona puede amarse a sí misma. En la historia del pensamiento unas veces este amor se ha valorado negativamente. Recuérdese al respecto el meollo del De civitate Dei agustiniano: 'dos amores fundaron dos ciudades, el amor de sí hasta el desprecio de Dios, la ciudad terrena; el amor de Dios hasta el desprecio de sí, la ciudad celeste'. Sobre esto Leonardo Polo ha escrito que «el hombre de baja condición lo hace todo por amor a sí mismo, y tanto más cuanto peor es; por eso, se le reprocha que no hace nada ajeno a su propio interés. En cambio, el bueno obra por el honor, y más cuanto mejor es, o por causa de su amigo dejando a un lado lo que le concierne; 
el mejor amigo es el que quiere el bien de aquél a quien quiere por causa de éste» (Polo, 2003: 189). Con todo, también cabe un amor positivo a uno mismo, como advirtió Aristóteles (Ética a Nicómaco, IX, 1168 a 2835 ; 1168 b 1-14) y como recuerda el autor recién mencionado: «cada uno es el mejor amigo de sí mismo; por tanto, debemos querernos sobre todo a nosotros mismos» (Polo, 2003: 189).

Amarse a sí mismo suele denotar egoísmo ${ }^{1}$, aunque, como se acaba de indicar, no siempre. ¿Cuándo no? Ya se ha señalado que el amor personal es entre dos personas, y que éste es más que bueno. Por tanto, ese amor no puede ser malo o egoísta. Ahora bien, uno no es dos personas, sino una. Por tanto, no puede darse el amor personal de uno para consigo mismo. Entonces, ¿de qué amor se trata cuando se habla de correcto 'amor de sí'? Se trata de dos tipos de amor: uno inferior y otro superior.

a) El inferior es el amor de la persona humana a su yo. El amor personal está a nivel de acto de ser, es la persona. Éste se distingue realmente, por activo y superior, de la esencia humana. Ésta no es la persona, sino de la persona. La esencia humana es lo que de ordinario llamamos yo, que también es activo y queriente. A éste se le designa también con la palabra personalidad, y equivale a lo que la tradición filosófica medieval llamó hábito innato de la sindéresis, mediante el cual activamos a la voluntad y a la razón. La persona no se reduce a su yo, pues uno conoce bien su yo, pero, en rigor, no sabe enteramente quién es como persona. El sentido de su yo depende de la persona, pero ella no depende enteramente de sí, porque su sentido personal no está en sus manos, ya que no es un invento propio, sino divino. La persona no es su personalidad; la persona es nativa y creciente; la personalidad, en cambio, es en buena medida adquirida; la primera es novedosa e irrepetible; la segunda, en cambio, admite tipologías comunes. La personalidad nace de la persona; no a la inversa. Pues bien, una persona humana se ama correctamente a sí cuando el yo o la personalidad que ella conforma en su esencia manifiesta el sentido personal propio en la medida en que éste lo va alcanzado. No se ama a sí con rectitud cuando se traza un yo que no responde al ser personal que es y está llamado a ser, y hace girar alrededor de ese yo todo lo demás.

Uno no se ama con corrección su yo sí, para eso, no toma su ser personal como modelo, es decir, si no modela el yo de acuerdo con su sentido personal y se aferra a un modelo de yo que no responde a su ser. 1 «El epíteto 'egoísta’ ha adquirido un sentido peyorativo, porque en su mayor parte
el amor a sí mismo es malo» (Polo, 2003: 189). 
Esto es erróneo; mal que - como se ve- nace del fondo de la intimidad personal. Como ese yo está despersonalizado y es él quien rige el trato manifestativo con las demás personas y con el resto de lo real, despersonaliza aquello a lo que se dirige, es decir, desecha el sentido personal. Esto significa, por ejemplo, que tal yo no puede ser amigo, porque amigo significa 'otro yo', pero 'otro yo' es claramente contrario a tal 'yo', el cual no admite 'otro', pues ese 'yo' no es el 'yo real' sino el 'yo idealizado': «el hombre sólo puede amarse a sí mismo si es bueno; el hombre malo no se complace en sí mismo si falta la posibilidad de algún provecho, que en rigor es diferente de él, pues lo que le aprovecha es un bien medial. Sólo en el hombre bueno la intención de otro es completa. Por eso la verdadera amistad va acompañada de virtudes, y sin ellas no es posible» (Polo, 2003: 190).

Querer al prójimo como a sí mismo, si se habla a nivel de esencia humana, es quererlo como 'otro yo', lo cual indica que se quiere aumentar su nivel de 'otro', a la par que se quiere aumentar la propia 'intención' de otro, es decir, su capacidad voluntaria de querer más otro. Sin esto no se entiende la amistad, pero tampoco la ética. Al yo idealizado, en cambio, le falta el jugar a favor del otro, porque le sobra petulancia. Pero este engreimiento - como se advierte-comporta en el fondo una confrontación personal con el Creador, porque es manifestación de que no se acepta ser quien se es y se está llamado a ser, es decir, no se ama el designio divino ${ }^{2}$.

b) El superior es el amor de la persona humana a sí en la medida en que es amada por la persona a la que ella ama. "Conviene hablar de unión proporcionada por la correspondencia: amarse como amante precisamente por saberse amado, puesto que sólo así el amor del otro no está obligado a destruirse. Y esto es la culminación de la felicidad. La unión es la mutua aceptación» (Polo, 2003: 208). Si amarse directamente a sí mismo es incorrecto por vanidoso, no lo es cuando es indirectamente, a saber, como muestra de agradecimiento de que Dios y las demás personas nos aman.

Nótese que en el amor correcto de sí se está abierto al crecimiento amoroso, porque los demás - el amor divino y el de otras personas- lo anhelan. Por eso, se comprende que San Agustín aconsejase que en temas de verdadero amor, 'si dijeses basta, pereciste'. En cambio, en el amor incorrecto de sí se erradica el crecimiento, porque la persona que se quiere ya ocupa la cúspide hegemónica. El amor a la propia excelencia se

2 «La petulancia de la esencia humana, aparte de ser incompatible con el jugar a favor que la caracteriza, comportaría confrontación con el Creador» (Polo, 2003: 208). 
opone también a la sabiduría, porque ésta crece en la medida en que descubre más sentido personal; en cambio, el apego a la propia excelencia inhibe el crecimiento, porque se mira más a lo logrado que a lo que queda por descubrir, y eso delata que la sabiduría decae. Como se ve, «la humildad tiene que ver también con el amor personal, el cual es superior al yo, que es la cima de la esencia humana: la sindéresis. El yo no implica egoísmo, pues la sindéresis es el principio de la actividad de la esencia del hombre, que no se queda en sí misma, a menos que se incurra en pecado» (Polo, Epistemología, creación y divinidad, pro manuscripto, 285).

Como se puede apreciar, ni en el amor correcto que se ha llamado 'inferior' ni en el 'superior' se da la 'reflexividad', la cual es contraria a la índole del amor, puesto que éste es — como se ha insistido- referencia a personas distintas.

\section{E1 amor personal a los demás}

El amor personal humano está naturalmente referido a Dios y a las demás personas. Respecto de la referencia a Dios el hombre carece de problemas de aceptación por parte de Dios, porque él siempre acepta el amor humano. En esta vinculación el problema, que no es nativo o constitucional, puede correr a cargo del hombre, si éste retira libremente su aceptación a lo largo de la vida. Sin embargo, la persona humana no es única, y aunque está abierta naturalmente a aceptar a las demás personas, el problema en este caso puede ser doble a lo largo de la existencia: o que uno no acepte a los demás, o que los demás no le acepten a uno. Pero estos problemas no son nativos en las personas, sino adquiridos durante la existencia.

El hombre convive con otras personas humanas y, como éstas no siempre aceptan su amor, aparecen inconvenientes en su vida, pues la convivencia no es fácil ${ }^{3}$. Antes de considerar la apertura de los demás hacia uno se requiere revisar la apertura propia hacia los demás. En efecto, más que preguntarse quién es el prójimo de uno, previamente hay que preguntarse de quién es uno prójimo, es decir, si considera a los

3 «El hombre, en tanto que es una criatura espiritual, también tiene ese problema. Por eso, el primer mandamiento de la Ley de Dios es: Amarás al Señor Dios tuyo con todo tu ser, con toda su fuerza, con toda su mente, con todas tus obras, y al El sólo servirás; te subordinarás exclusivamente a Él. Pero ése no es el único problema que tiene que resolver el hombre: ha de encarar además otro problema, que es precisamente el de la convivencia con sus semejantes» (Polo, 1996c: 72). 
demás como personas amables ${ }^{4}$. «Amar al prójimo como a uno mismo; comportarse con los demás como uno quisiera que se comportasen con él; no es una especie de sistema de defensa mutua, de no agresión, sino manifestación de una acción efusiva. Doy de la plenitud que tengo porque tú eres mi prójimo; pero sólo serás luego prójimo mío si tú también efundes la plenitud que han comenzado a recibir» (Polo, 1996a: 114). En efecto, «la estructura del amor en cuanto acto perfecto implica una respuesta: alguien que esté a la altura de la donación, alguien para el que la donación sea no sólo recibida. La donación no es mera beneficencia, sino que implica una intención dignificante que se concentra en la idea de prójimo» (Polo, 2011: 64).

El concepto de prójimo comporta, por una parte, notar que alguien es una persona que está vinculada natural y amorosamente al amor divino, y, por otra, cierto desconocimiento acerca de si su vínculo con Dios es más o menos estrecho que el nuestro. Se suele hablar de 'igualdad' entre los hombres, y en ella se suele basar la dignidad, pero si la igualdad es exclusivamente mental y no real, habría que indicar que se es más o menos digno en la medida del vínculo amoroso de cada quien respecto del ser divino. Pero este extremo sólo el ser divino lo conoce, de modo que no podemos juzgar las intimidades ajenas. Además, lo peor es considerar que los demás no estén constitutivamente abiertos a Dios: es la vieja pretensión de ser la única criatura espiritual ${ }^{5}$.

No se ama a los demás si sólo se quieren las cualidades que manifiestan, pues muchas de esas cualidades en modo alguno son deseables, porque son defectuosas, e incluso viciosas. Efectivamente, si se quiere a los demás por sus propiedades, el amor es problemático, porque no es personal, ya que tales cualidades (belleza, simpatía, profesionalidad, eficacia, etc.) no son la persona, sino de la persona, y además, están sometidas a fluctuaciones existenciales. Hay que amar a los demás por su persona, es decir, por su acto de ser, más que por su esencia y naturaleza humanas. La primera, mientras se vive, siempre está abierta a Dios, aunque según un más y un menos libre, y también responsable. Las otras, en cambio, ofrecen no pocas veces en varias facetas cerrazones problemáticas a la divinidad, y éstas en modo alguno se deben amar, sino ayudar a corregir.

4 «Una de las categorías fundamentales de la sociología cristiana es la noción de prójimo. Esta noción significa que, si yo soy un ser capaz de amar, el otro ha de ser tal que no sea inferior a mí, o privado de esa capacidad» (Polo, 1996b: 134).

Pero «la pretensión de ser la única criatura espiritual es pecado. Para amar hay que amar lo que ama Dios, y de esta manera el hombre se encuentra vinculado a la realidad creada» (Polo, 1996a: 92). 
A nivel de esencia y naturaleza humanas hay que hablar de 'amistad', más que de amor personal. Ésta es una virtud de la voluntad, la superior, que se acrecienta, por una parte, con el trato: «la esencia de la amistad reside en el compartir, en el conversar y en el compenetrarse. En ella el hombre se encuentra en la misma relación respecto del amigo que consigo mismo. Por eso Aristóteles sostiene que el amigo es otro yo, idea que repite Cicerón» (Polo, 2003: 188). La amistad es respecto de los hombres, no respecto de animales o cosas, porque sólo los hombres son 'otro yo' y pueden responder como tales a la amistad. «Sin duda se puede querer una silla; quererla más significa enfocarla como mi silla favorita. Pero la silla apenas justifica esa consideración; en rigor, no es posible aumentar la alteridad de la silla porque se trata de un medio y, por tanto, de un bien finito. En cambio, la co-existencia con otras personas es incrementable de acuerdo con querer-yo. Como observa Agustín de Hipona, cuando se trata del amor nunca digas basta» (Polo, 2003: 203).

La amistad crece, por otra parte, en la medida en que tiene como norte la verdad, no el interés. Por eso «son incompatibles con la amistad la adulación, la zalamería y el servilismo, pues son contrarios al amor y a la verdad»(Polo, 2003: 188). Por eso quienes están más abiertos a la verdad, se hacen más pronto y más intensamente amigos, y su amistad decae menos. Es tradicional decir que los filósofos buscan la verdad ${ }^{6}$. Con todo, es manifiesto que entre los diversos 'filósofos' a lo largo de la historia del pensamiento occidental, y también entre los actuales, ha habido y hay no sólo polémicas teóricas, sino incluso faltas manifiestas de amistad, más o menos cubiertas por las apariencias externas. Las faltas de amistad se dan cuando los diversos pensadores son más 'amigos' entre sí que de la verdad, lo cual implica que son menos filósofos, es decir, que el norte del querer de su voluntad no es la verdad, sino el interés. En esa tesitura su vinculación da lugar a escuelas, pero éstas, si bien se mira, son lo más opuesto a la índole de la filosofía, porque la filosofía debe estar abierta a toda verdad. La actitud de querer formar

\footnotetext{
6 «¿Qué es la filosofía? Es un tópico decir que es el amor a la sabiduría (éste es su exacto significado en la lengua griega: filía es amor, y sofía es sabiduría). La filosofía, propiamente, no es sabiduría, sino amor a ella. La filosofía no es un saber terminativo o culminativo, entre otras cosas, porque eso trasciende nuestras posibilidades en esta vida: no podemos agotar la verdad, sino que tendemos a ella y vamos incrementando nuestro conocimiento de la misma (el conocimiento, o es conocimiento de la verdad, o no es conocimiento de nada)» (Polo, 1995: 15). «La filosofía es el amor a la verdad, la búsqueda de la verdad. La filosofía se ocupa de la verdad de modo global, sin restricciones. Lleva consigo una actitud sin la cual el amor a la verdad no aparecería, o estaría condicionado por otros intereses; el amor a la verdad tiene que ser sincero, auténtico» (Polo, 1995: 21).
} 
escuela denota, en el fondo y aunque no lo parezca, falta de formación, porque «el amor a la verdad es lo más importante en la formación de un hombre» (Polo, 1997: 47) ${ }^{7}$, y la verdad, como trascendental que es, es de máxima amplitud.

Por otra parte, si la sabiduría es una persona en vez de una mera verdad racional conocida, entonces la filosofía que se trabaja es amor personal. Hay que distinguir entre querer y amar. Amar es respecto de personas. Si simplemente se quiere la verdad, es señal que detrás de ésta no se ven personas. Si se la ama, entonces se conoce que la sabiduría o verdad es personal. Y como la persona es lo superior en toda la realidad, en esa tesitura uno se juega no sólo su trabajo, sino también su vida por dicha verdad. En este caso ya no se trata meramente de un 'deseo' de verdad, o de un 'quererla', sino de un compromiso personal con ella; de amor: «el amor a la verdad es mucho más que el deseo de verdad, es un servicio a la verdad. La verdad es el fundamento del valor. Me acerco a las cosas porque valen, pero valen porque son verdaderas. La relación con la verdad no es meramente constatativa, sino amorosa. La verdad despierta en el hombre un dinamismo que también salta a la vida eterna. La verdad teórica mejora a la vida práctica, no sólo establece las reglas de juego sino que se extiende al amor» (Polo, Acción y contemplación, pro manuscripto, 3).

\section{La apertura amorosa a Dios}

«Se trata ahora de enfocar el más importante de todos los temas: Dios. Dios es el Ser respecto del cual nosotros los hombres (aparte de otras muchas cosas) nos jugamos el tipo, por activa y por pasiva. Por activa, si estamos dispuestos a amarle y a cumplir su voluntad, tensándonos hacia Él. Y, por pasiva, si no lo estamos. Porque el que no lo está, o deja de estarlo, perece sin remedio» (Polo, 1993: 40). La persona humana está constitutivamente abierta al ser divino, porque si no lo estuviera originariamente, jamás podría estarlo con el correr del tiempo biográfico, ya que estarlo es superior a no estarlo, y lo superior

\footnotetext{
7 Con todo, todavía cabe una actitud peor al 'escuelerismo': considerar que aquéllos que se adhieren a la verdad venga de donde venga hasta dar la vida por ella conforman una especie de rara 'secta'. Pero esta actitud no es más que una extrapolación en los otros, a los que no entienden, de la propia idea no justificada de 'filosofía'. En esa tesitura, sin el norte de la verdad, la amistad del grupo así conformado no es 'verdadera' amistad. Por lo demás, quien ama la verdad tal de la manera indicada considera una friolera el que se diga que él forma parte de una secta, sencillamente porque como él ama la verdad, y esta afirmación es un error, no le da importancia.
} 
no puede surgir de lo inferior. Si no lo estuviera originariamente, habría que decir, que tal apertura es exclusivamente fruto de 'don sobrenatural' divino acaecido en el tiempo (como han defendido, por ejemplo, Kierkegaard, Ricoeur o Grimaldi), pero como esa donación se considera una añadidura, no una dimensión natural, resultaría que unos hombres estarían abiertos a Dios por don divino y otros no, y como estarlo se considera superior a no estarlo, porque esa apertura es amorosa y conlleva correspondencia amorosa, es decir, felicidad, ello denotaría que Dios es injusto, pues a unos dota de felicidad, mientras que a otros les priva de ella. Pero como un Dios injusto no es Dios, conviene mantener que la persona humana está nativamente diseñada como apertura amorosa a Dios, amor que, además, es creciente.

La anterior tesis antropológica, que fue mantenida a lo largo de toda la tradición filosófica clásica y medieval, se rompió en los albores de la modernidad con Guillermo de Ockham. Y, por eso, «lo que se concreta de manera definitiva en Ockham es el pesimismo antropológico. El pesimismo antropológico por excelencia es la tesis según la cual el hombre no tiene nada que hacer respecto de Dios porque no puede amarle con toda su mente» (Polo, 1993: 60). Como se sabe, en este y otros puntos, la sombra del padre de la 'via modernorum' es muy alargada, pues llega hasta nuestros días, ya que su tesis ha sido asumida y repetida por influyentes autores (Lutero, Kant, Kierkegaard, etc.) y por no pocas corrientes de pensamiento (por ejemplo, los empirismos materialistas de todas las épocas). Si se cierra la apertura noética y amorosa a la trascendencia divina, desde ese momento la filosofía mira de tejas para abajo, es decir, la mirada y afecto del hombre se vierte sobre lo que él puede dominar. Pero la contrapartida de esta actitud es que con ella no se alcanza la felicidad y comparece el desamor y la perplejidad.

Si el amor a Dios es nativo y creciente, esto indica que es una perfección radical del hombre, es decir, de su persona o acto de ser, no una perfección adquirida en su esencia (voluntad) con la posterior activación y ejercicio de esta potencia. Lo que precede significa que, así como no se llega a ser persona sino que se es 'ab initio', del mismo hay que decir que no se llega a ser amor, sino que se es originariamente amor: cada persona creada es un amor nativo distinto. Si tal perfección es nuclear o radical, entonces, «amar a Dios es trascendental en tanto que la persona prefiere a Dios; esa preferencia es dilectio. Por más que la persona humana no sea capaz de hacer de su amar un don trascendental - pues puede dar su amor a modo de don, pero no convertir ese don en persona-, aún así, el amor está en la persona en estado de espera, es decir, como amar en busca de aceptación. El amar espera ofrecer el don, y que ese don sea aceptado» (Polo, 1999: 227). 
Si bien tal apertura amorosa de la persona humana es nativa, a lo largo de la vida la persona puede mantenerla y acrecentarla. Por eso, cansarse de amar conlleva en el fondo olvidar a Dios. Para mantener y acrecentar esa apertura, el hombre tiene que vencer las rémoras tanto de su naturaleza y esencia humanas como las de los demás: «si, efectivamente el hombre es capaz - para esto tiene que superar las concupiscencias, o al menos luchar contra ellas- de amar a Dios más que a sí, o, para expresarlo de una manera un poco más neutral: si el sentido de la vida del hombre es sin envidia, si el hombre está dispuesto a recibirlo con plena aceptación, que es libertad, entonces el hombre alcanza por fin a ser trascendentalmente libre» (Polo, 1996a: 266).

Sólo el amor de Dios puede otorgarnos la felicidad, porque sólo su amor - no el de otra persona creada - nos puede aceptar enteramente, si nosotros libremente lo aceptamos. En efecto, el amor personal humano no se puede cumplir queriendo una cosa, porque éste, más que amor, sería querer un bien. A la par, ninguna persona creada es capaz de aceptar irrestrictamente el amor personal de otra persona, entre otras cosas, porque desconoce la irrestricta hondura del amor como acto de ser personal. «De manera que la persona humana es viviente buscando la réplica y encomendando la aceptación a Dios» (Polo, 2003: 81).

Por otra parte, si el amor del acto de ser personal humano a Dios es la clave de la felicidad humana que se espera alcanzar definitivamente tras esta vida, éste amor redunda o se desborda sobre la esencia humana, hasta el punto de que «sin la búsqueda personal de Dios, la esencia humana no sería relevante... Abismarse en la réplica es un encuentro eternamente inacabable al que la esencia está asociada. Sin esa esperanza, el encuentro esencial sería un fracaso, que la persona no puede justificar. Esta observación vale también para el amor y para la vida... El amor está a la espera de la aceptación divina. Asimismo, esta vida no es la más alta para el viviente, que espera una vida más plena después de la muerte» (Polo, 2003: 81). La esencia humana crece por la progresiva activación que sobre ella ejerce el acto de ser, o sea, la persona. Si el acto de ser es elevado, inexorablemente tal elevación redundará sobre la esencia humana. Recuérdese: lo superior, el acto, explica el crecimiento de lo inferior, las potencias; no a la inversa.

Pero en la presente situación el amor personal humano no es definitivamente aceptado por el ser divino. Por eso, hay que seguir buscando y aceptando el amor divino: «buscar, en rigor, es no detenerse en sí mismo... Para caracterizar la búsqueda suelo emplear el término destinación, porque estimo que significa más que mirar al fin. Dicho de otro modo, detrás del bien está el amor. Descubrir el amor es vislumbrar a Dios» (Polo, 2003: 204). El bien tiene sentido de 'fin', porque no es 
personal; en cambio, el amor tiene sentido de 'destino', porque es personal.

\section{La elevación de la apertura amorosa a Dios}

El amor natural es distinto del sobrenatural, porque el primero es nativo o creatural y el segundo recibido como don divino a partir de determinados momentos de la vida. Con todo, el segundo es la elevación sobrenatural del primero. El amor personal es elevado sobrenaturalmente por medio de un don divino: la caridad. Ser elevado indica ponernos de algún modo a la altura de Dios. Con este don apreciamos que Dios también es caridad. Este don conlleva unión personal con Dios, es decir, no concebir al ser divino como heterogéneo respecto de la persona humana. Recuérdese que para Lutero Dios no es susceptible de caridad con el hombre, sino sólo de compasión ${ }^{8}$. Téngase en cuenta asimismo que esa misma tesis la atribuye Nietzsche a la voluntad de poder?.

Como es sabido, la caridad está vinculada a otros dos dones asimismo de índole sobrenatural: la fe y la esperanza. Son dones que no inhieren en la inteligencia o en la voluntad, potencias de la esencia humana, sino en el acto de ser personal humano ${ }^{10}$. Cada uno de ellos eleva un radical personal distinto: la esperanza, a la libertad personal; la fe, al conocer personal; la caridad, al amor personal. Con ellos esperamos, conocemos y amamos al Dios pluripersonal que con ellos se nos revela. Así como los tres radicales personales aludidos conforman el co-acto de ser personal humano, y no se pueden comprender separadamente, así los tres dones sobrenaturales mencionados están íntimamente entrelazados. Por eso, para explicar uno hay que hacer referencia a los otros. En efecto, «el amor del hombre es un amor de esperanza: mira a la correspondencia, es decir, a una aceptación más donal que el amor humano» (Polo, 2003: 148). A la par, la caridad es un amor lúcido, pues

\footnotetext{
8 «La caridad no es posible en Lutero: el hombre es incapaz de ella. En el luteranismo la caridad es tan sólo la misericordia divina, pero el hombre no es sujeto de caridad, ya que no puede amarse más que a sí mismo» (Polo, 1996b: 62).

9 «El amor a Dios es también inaceptable para Nietzsche, en virtud de su visión de la voluntad de poder como 'voluntad de poder y nada más'. El amor implica una dualidad que consagra por completo al otro y, por tanto, lleva la subordinación al paroxismo» (Polo, 2005: 117). «El amor, la tendencia al bien, son calificados por Nietzsche de farsas» (Polo, 2005: 124).

10 «El amor es superior a cualquier acto de querer, incluso si es un acto de la virtud de la piedad» (Polo, Epistemología, creación y divinidad, pro manuscripto, 129).
} 
está acompañado de la luz de la fe, la cual permite conocer mejor a las personas divinas. Por el contrario, si se considera que la fe no es cognoscitiva, o que es 'quia absurdum', error propio del fideísmo (Tertuliano, Ockham, Lutero, Kierkegaard...), el sentimiento resultante en el espíritu es la tristeza: «la 'tristitia espiritualis' o acidia se refiere, precisamente, al trato con Dios; es decir, una gelidez del corazón. La frialdad amorosa es intolerable, es una situación inadecuada» (Polo, 2007: 205).

El don de la caridad es inmerecido, pero Dios sólo lo da al que está dispuesto a aceptarlo, pues darlo para que sea rechazado carece de sentido. Esto indica que el don requiere correspondencia: «mi aceptación tiene que ser aceptada a su vez por Dios: por su amor misericordioso. El don se da en la reciprocidad y ésta debe mantenerse continuamente» (Polo, Epistemología, creación y divinidad, pro manuscripto, 186). Con el amor natural la persona se transciende a sí misma; con el sobrenatural vive en cierto modo la vida divina. En este nuevo estado uno se da cuenta que el amor divino es la realidad suprema: «cuando se trata de enamorarse de Dios tiene un carácter de considerar que Dios es el único que merece la pena, para la gran capacidad del amor humano. Y ahí está el Espíritu Santo para aumentar el amor, y para sobrenaturalizarlo» (Polo, La afectividad, pro manuscripto, 15).

Lo que precede indica que en la situación definitiva a la que la persona humana está llamada prevalece la caridad. Pero si este don sobrenatural es hegemónico en aquella tesitura, hay que indicar también cual de las tres virtudes sobrenaturales caracteriza más a la presente vida $\mathrm{y}$, asimismo, si se da alguna otra situación humana en la que prevalezca la tercera de ellas. Recuérdese que a este respecto la Iglesia distingue tres estados: la vida en la tierra, la del cielo y la del purgatorio: «una de las diferencias entre estos tres estados de la Iglesia puede cifrarse en la virtud infusa prevalente en cada una de ellas. En la celeste desaparecen la fe y la esperanza y permanece únicamente la caridad. En la purgante, la virtud principal es la esperanza segura. En la militante se dan las tres, y tiene especial importancia la fe» (Polo, Epistemología, creación y divinidad, pro manuscripto, 261).

Sin embargo, como la presente situación no es la definitiva, la persona humana puede perder el don divino de la caridad. Por lo tanto, debe estar siempre atenta a él: «la caridad divina incluye la atención, el tener en cuenta que hace ser. Pecar consiste en el aislamiento, en el romper la propia vocación expresiva que está fundada en la conversación universal. Dios escucha todo. Escuchar es dar dignidad a las cosas. Al hombre lo reúne, le hace estar consigo, la conversación con Dios. El hombre que abandona el Infinito se pierde a sí mismo y queda a merced de sus rabietas, apartado de sí» (Polo, 2009: 298). Una manifestación 
externa de esa pérdida es el trueque de la caridad por el sentimentalismo: «cuando la caridad se enfría, suele incurrir en rigidez, y pierde su jugo vital o se reduce al sentimiento de filantropía» (Polo, 2003: 191).

Si la caridad es la situación definitiva a la que el hombre está llamado y la puede comenzar a vivir en esta vida, se puede decir que es lo que más describe el ser de la persona humana: «¿Qué soy, pues, yo? La posibilidad de amar a Cristo, digamos. Pero no como a un objeto amado, sino como a mi Amante. Este es el quid. Mientras que en la escala humana yo amo a otro y ese otro me ama a mí, de tal manera que la interclusión de la noción de otro - la distinción de personas humanas-es solidaria de la imposibilidad de coincidencia plena entre el otro como objeto de mi amor y el otro como mi amante - yo le amo a él y él me ama a mí, pero su yo no existe en el mismo sentido en que es objeto de mi amor-, mi amor a Cristo - yo- se dirige a Él como a mi Amante, es decir, que mi amor está encerrado en la pura prioridad de que El me ama, es decir, en El mismo - pues es mi mismo yo quien es miembro suyo-. La razón de que yo le ame es El como amante. No la excelencia de un ser fuera de mí, sino El mismo nacido en mí como amante. Si El no existe fuera de mí, es porque su Existencia es mi amante-amado. Yo soy sólo una respuesta existencial. Soy en el modo de no distinguirme de su expresarme. El ha querido que ese expresarme se identificara con El, hacer oír la voz con que me llama, es decir, llamarme» (Polo, 1996a: 248).

\section{El amor personal divino respecto del hombre}

En Dios no existe voluntad, sino amor personal, porque en él no hay potencias sino acto. Si se ha indicado que en el hombre el amor no es de la voluntad (de la esencia) sino personal (del acto de ser), es claro que también lo es en Dios. Con todo, multitud de autores a lo largo de la historia del pensamiento occidental han atribuido la voluntad a Dios -Tomás de Aquino, por ejemplo-. Pero esta tesis no se puede aceptar si se toma la voluntad en sentido estricto, es decir, como 'potencia'. Otros, en cambio, no han atribuido la voluntad a Dios -Aristóteles, por ejemplo- por considerar que esta potencia es imperfecta por desiderativa $^{11}$, pero tampoco han considerado que Dios sea amor.

11 «[Aristóteles] más bien dice que el amor, entendido como órexis, corresponde a la relación de todo lo demás con Dios. El primer motor mueve en tanto que es amado; ese amor dirige la asimilación a él, que sólo puede ser teórica. Pero en el primer motor, que es inmóvil, pura intelección, no hay amor porque tampoco existe un respecto desiderativo hacia el resto de la realidad. Con otras palabras, Dios no tiene voluntad 
La visión cristiana de la voluntad difiere de la griega porque considera que la voluntad es, como la inteligencia, susceptible de ejercer actos perfectos (operaciones inmanentes y virtudes), sin mezcla de potencialidad $^{12}$. Con todo, ninguno de sus actos despotencializa por entero a la facultad, es decir, ésta no deja nunca de ser 'potencia'. Por tanto, en rigor, no se puede decir que Dios tenga voluntad, al menos como la nuestra. Si se le atribuye voluntad, hay que verla como amor, es decir, como acto de ser sin mezcla de potencialidad. Y como las dimensiones del amor personal son tres: aceptar, dar y don, ninguna de estas tres son pasivas en Dios, sino activas: «Dios es bueno simpliciter porque el amar, el aceptar y el amor son eminentemente reales en Él. Sostengo que para poner la voluntad en Dios conviene tener en cuenta la estructura donal» (Polo, 2003: 147).

Por tanto, si Dios no es voluntad sino amor, en rigor, Dios no 'desea' nada respecto del hombre, tampoco respecto de la creación. De modo que hay que concebir todas las manifestaciones externas divinas (creación, elevación, divinización...) como manifestaciones del amor personal divino. En efecto, por una parte, la creación, es -como la describió Tomás de Aquino- 'donatio essendi': «la criatura no es una parte de Dios (Dios no tiene partes), sino realidad otorgada. El otorgamiento es tan radical como la realidad. Por eso se dice que la criatura no se presupone: se crea de la nada» (Polo, 1996b: 131). Por otra parte, la Encarnación también hay que verla como una muestra del amor divino, no como requerimiento o necesidad suya: «el Amor es la única razón posible de la Encarnación... El amor es una iniciativa, no un puro despertarse ante lo deseable, sino que tiene una fuente íntima»(Polo, 2011: 63$)^{13}$.

porque la voluntad, a diferencia de la inteligencia, es imperfecta, y en Dios solamente se pueden poner las perfecciones puras» (Polo, 2003: 95).

12 «Dice Tomás de Aquino que, más o menos, todos los filósofos vislumbraron que Dios es Logos, pero que Dios es Amor no lo vislumbró ninguno. Es claro que si la voluntad es tendencia y deseo solamente, no cabe ponerla en Dios (un dios deseante es una noción mítica o una ilusión gnóstica aberrante), porque de ello se sigue que Dios es imperfecto, y un dios imperfecto es una contradicción. Sin embargo, el cristianismo sabe que Dios es Amor» (Polo, 1996b: 129).

13 En otros lugares escribe: «lo primario, la noticia revelada, es, con el misterio trinitario, la Encarnación de Dios. Pues bien: ¿cuál es la razón de ser del teandrismo, de la existencia del Dios hecho hombre? Esa razón de ser no puede ser más que el amor, y éste es el punto en que el cristianismo incide de un modo completamente innovante, como algo insospechable e inesperado. Es lo que expresa de manera literal San Juan: Dios es amor» (Polo, 1996b: 128). «El teandrismo, es decir, el planteamiento radical del tema del hombre en el cristianismo, solamente es posible si Dios es Amor. Dios no se hace hombre por necesidad ni por deseo. Dios no necesita en modo alguno encarnarse. 
En cuanto al hombre, por un lado, la creación de éste por parte de Dios hay que concebirla como muestra del amor divino: «si somos genéticamente improbables, pero somos personas (no casos empíricos), se ha de admitir que somos objeto de predilección divina. Lo único que puede explicar nuestra existencia es un amor especial que nos hace ser a nosotros y no a otros (no hay ninguna otra explicación racional posible de nuestra contingencia genética)» (Polo, 1995: 221) ${ }^{14}$. En los vegetales y animales no ocurre esto, puesto que no son personas, y la persona es una novedad radical, sin precedentes ni consecuentes. Por otro lado, la elevación del hombre en esta vida por parte de Dios también hay que verla como manifestación amorosa divina: «existe otra donación divina, una iniciativa todavía mayor (que su creación), por la que Dios introduce al hombre en su Vida íntima. El estudio de tal elevación pertenece a la Teología de la Fe. En el propuesto planteamiento de la antropología trascendental se sostiene, aun sin estudiar in recto esa elevación, que la aceptación divina del ser humano salva la distancia de la criatura al Creador. Esa distancia es, por así decirlo, infinita. Con todo, la persona humana es tenida en cuenta por Dios, venciendo así el aislamiento que es incompatible con la radicalidad del ser personal» (Polo, 1999: 222).

De modo semejante hay que entender otras prerrogativas divinas atribuidas tradicionalmente a Dios por parte de la teología natural. Así, por ejemplo, la omnipotencia divina: «en Dios la omnipotencia debe entenderse como misterio de amor donal. Con esto, las interpretaciones panteístas caen sin más» (Polo, 1999: 135-136). Y asimismo cabe entender la divinización definitiva del hombre en el cielo de la que habla la teología sobrenatural: «el cristiano se identifica con Dios, pero no por confusión, sino por comunicación en el amor. Todo desaparecerá, excepto la caridad: Dios me ama, yo amo a Dios: hay una profunda identidad, pero que no es identificación o confusión cosística, porque la salvación no depende sólo de Dios —así es el luteranismo-, sino que

Se trata de un puro otorgamiento, de la generosidad ontológica perfecta, como afirma San Pablo en el capítulo II de la Epístola a los Filipenses» (Polo, Epistemología, creación y divinidad, pro manuscripto, 36). «Desde la fe se ha de decir que Dios, como fuente de amor, desea darse a conocer, y el conocimiento verdadero que el hombre tiene de él es la culminación de cualquier otro conocimiento verdadero sobre el sentido de la propia existencia que su mente es capaz de alcanzar» (Polo, Epistemología, creación y divinidad, pro manuscripto, 49).

14 «Crear al hombre es donar un ser personal que, co-existencialmente, es aceptar y dar» (Polo, 1999: 220). "Cada quién es un don debido al amor de predilección. La persona humana es una novedad radical porque es creada directamente por Dios. El contraste entre los hombres posibles que no llegan a ser y los que son, pone de manifiesto la dignidad personal y su dependencia de un amor divino de predilección» (Polo, 1999: 205). 
depende de Dios, pero en cuanto me hace capaz de El» (Polo, 1996a: 114). En suma, la entera realidad es una cuestión de amor, y la falta de ella es una carencia de amor.

\section{La misericordia divina}

La misericordia no es compasión, pues ésta mira lo inferior como tal, mientras que la primera lo eleva. Para ilustrar la índole de la primera se puede acudir al pensamiento nietzscheano: «Nietzsche dice que un sol es frío para otro sol. Eso es la negación de la intersubjetividad. ¿Qué queda entonces? Zaratrustra solo, bajando de la montaña. Pero bajar de la montaña es un acto de compasión, no de misericordia. Aunque muchas veces estas palabras se usan como sinónimas, conviene distinguirlas. La compasión es un sentimiento o una actitud ante el inferior, renunciando a que el inferior deje de serlo; la compasión es lo único de que es capaz el superior cuando no puede establecer una relación con el inferior como su igual. Pero eso lleva a la desesperación. El Así babló Zaratrustra, que desde muchos puntos de vista es un libro genial, es nulo en lo que se refiere al destino» (Polo, 2007b: 255).

En cambio, para ilustrar la segunda, la misericordia, es pertinente considerar algunos puntos clave de la revelación divina: la creación, Encarnación, elevación y glorificación. Atendamos, por una parte, a la creación de cada persona humana. El que la índole de la persona creada sea imagen de la divina es manifestación de la misericordia divina: «la noción de persona creada solamente es explicable por la misericordia de Dios. Y la cuestión se concentra entonces en que la persona humana es inferior a Dios. ¿Cómo es el acto creador de la persona humana? El acto creador de la persona humana es omnipotente y misericordioso: donal» (Polo, 2007b: 255). Por otra parte, tras crear Dios al hombre, no se conforma con dejarlo a su nivel, sino que lo eleva a sí, lo cual es una muestra todavía superior de su misericordia: «como Él es omnipotente y misericordioso, otorga a nuestro amor una altura elevada a la de Él, sin la cual nuestro amor no sería nada, porque no valdría para Dios. La donalidad de Dios es superabundante... Dios no puede dejar que la persona se quede ahí, como inferior, porque entonces la misericordia se transformaría en compasión. La entera dinámica de la Encarnación no tiene sentido si no es así. Cristo, por lo mismo que es nuestro Redentor, es nuestro elevador. Si la persona no cuenta para Dios, ser persona es una desgracia» (Polo, 2007b: 255).

Además de como amor, la misericordia divina también se puede entender - desde el punto de vista humano- como un afecto espiritual 
divino: «el amor de Dios es radicalmente misericordioso y, al menos, según nuestro modo de entender, la misericordia se puede asimilar a un afecto. El amor misericordioso se puede apreciar en la Encarnación de Cristo y también en la Creación. Así pues, cabe hablar de afectividad divina, ante todo, en su relación con la criatura. En lo que respecta a la afectividad intratrinitaria, la cuestión es sumamente difícil» (Polo, Epistemología, creación y divinidad, pro manuscripto, 109). Es conveniente que la misericordia acompañe al amor divino, porque el hombre es susceptible de muchas miserias, nativas en su naturaleza y esencia humanas, y adquiridas además de en esas dimensiones, también en el acto de ser personal: «la misericordia ha de acompañar a la caridad, porque los hombres no estamos exentos de miserias; también a las demás virtudes: por ejemplo, la justicia sin la misericordia es demasiado severa» (Polo, Epistemología, creación y divinidad, pro manuscripto, 287).

El crear muestra más omnipotencia divina. En cambio, crear al hombre a semejanza divina es fruto de la misericordia divina, y también lo es el elevarlo. Pero estas manifestaciones del amor divino también se ven en la llamada providencia divina, es decir, en la protección de Dios al hombre a lo largo del curso histórico: «en la providencia sobre la historia resplandece máximamente el amor misericordioso de Dios» (Polo, 2008: 119). También se puede ver la misericordia divina en la aceptación divina de las obras humanas, porque éstas tienen de ordinario poco valor, pero al ser aceptadas por Dios, son elevadas de nivel: «la ética, desde el punto de vista de la persona, es el carácter oferente de la propia actividad, la reiteración del don por parte mía, al que Dios dota de un valor que no tiene en sí mismo, porque El es misericordioso» (Polo, 2012a: 295). Dios nos da esperando nuestra aceptación, y eso manifiesta su misericordia. Sin ésta Dios no crearía, porque crear, por naturaleza, es crear lo inferior a Dios. Pero si Dios crea al hombre es para elevarlo, eso indica que la creación está en función de la elevación. Y si Dios crea por amor y eleva por misericordia, cabe decir de algún modo que el amor divino está en función de su misericordia. En la creación se muestra más el dar del amor divino; en cambio, en la elevación se manifiesta más el aceptar divino.

De modo semejante al divino, la misericordia humana conlleva que no veamos a los demás como inferiores, sino personas del mismo nivel o superiores a nosotros. En virtud de ello, nuestras obras de servicio no serán raquíticas sino encumbradas: daremos lo que podamos. En nuestro caso, «la misericordia se ha de manifestar con obras que busquen remediar tanto las necesidades materiales (dar de comer al hambriento, visitar a los enfermos...) como las espirituales (aconsejar, consolar, confortar...). Para tratar de esta manera a los demás se requiere la humildad: no considerarnos superiores a ellos» (Polo, Epistemología, creación 
y divinidad, pro manuscripto, 287). Y como el dar está en función del aceptar, lo que demos tendrá mayor valor en la medida en que sea aceptado por los demás.

En suma, si se concibe a Dios como inaccesible (como, por ejemplo, Ockham) o como heterogéneo o 'totalmente otro' respecto de nosotros (como, por ejemplo, K. Barth o Horkheimer), la esperanza humana deviene problemática. Pero ésta no lo es, porque se basa en la misericordia divina ${ }^{15}$. Y otro tanto cabe decir, consecuentemente, de la alegría $^{16}$. Si en el epígrafe precedente se concluía que la entera realidad es una cuestión de amor, en este se puede concluir que, dado que la misericordia es una neta manifestación del amor divino, es «el único criterio para la vida» (Epistemología, creación y divinidad, pro manuscripto, 254) humana.

\section{El amor pluripersonal divino (I): el Dar y el Aceptar}

Se ha indicado que el amor personal dice referencia personal. De modo que no puede existir un solo amor, como asimismo es imposible que exista una única persona. Un amor sin otro amor no es amor personal: «el aspecto verdaderamente radical y profundo del amor estriba en no conservar la referencia a sí mismo, sin salir o escaparse de sí. En ese escaparse de sí se constituye la noción de lo otro en términos amorosos» (Polo, 2012b: 330). La pluralidad de personas es exigida por el amor personal, pues «en rigor, no se puede amar más que al otro; y amar, si el amor es una operación capaz de subsistencia, da la subsistencia a otro» (Polo, 2012b: 337). Se suele decir que el amor personal requiere de 'otro', pero si bien a nivel de la voluntad y de su virtud de la amistad (o sea, en el plano de la esencia humana) al amigo le cabe bien la expresión aristotélica de 'otro yo', a nivel personal (de acto de ser) a esa descripción sería preferible otra denominación que, más que la alteridad, marcase la íntima unión entre los que se aman, ya que no sólo es activo el amor del amante, porque la persona amada es a su vez amante, pues, como se ha

15 «La esperanza cristiana no es petulante, porque se basa en la misericordia de Dios» (Polo, 1996a: 114). En otro lugar escribe: «Esperanza, porque el desembocar la muerte en la vida eterna no se debe a nuestros méritos, sino a la misericordia de Dios» (Epistemologia, creación y divinidad, pro manuscripto, 239).

16 «La alegría cristiana no es un estado de ánimo sino un estado del ser, porque no se funda en nada de lo que nos acontece, en la fortuna o en la salud, sino en la activa misericordia de Dios, manifestada en Jesucristo y plenamente efectiva para nosotros» (Epistemología, creación y divinidad, pro manuscripto, 262). Cfr. asimismo, Polo, 1996b: 285. 
dicho, el amor exige la correspondencia. Pues bien, según esta estructura del amor personal humano, hay que decir que en Dios es absolutamente imposible que exista una única persona, y que, por tanto, al menos deben existir dos.

También se ha indicado que las dos dimensiones trascendentales del amor personal humano son el dar y el aceptar. Si en Dios estas dimensiones reclaman pluralidad de personas, una de ellas debe ser más afín al dar y otra al aceptar. La revelación cristiana nos ayuda a comprender mejor a las personas divinas, pues nos dice que una es el Padre y otra el Hijo y que ambas están enteramente referidas. Si las comparamos a las aludidas dimensiones del amor personal humano, el dar es más afín al Padre y el aceptar al Hijo. El Padre engendra al Hijo, lo cual denota donación, y el Hijo es la completa aceptación del Padre, lo cual también indica donación. Dar es aceptar la propia entrega personal, y aceptar es dar aceptación. Dar y aceptar denotan, pues, donación. De modo que la clave del amor radica en la donación, porque el amor es exuberante, no carente. En efecto, lo propio del amor es la completa entrega personal, no el quedarse en sí. Una persona que ama se da enteramente a la persona amada y, a la par, la persona amada acepta completamente a quien la ama.

Dios no puede ser una única persona, no sólo porque eso es contrario - como se ha adelantado- al amor personal, sino porque ese modelo supondría la sublimación del egoísmo, ya que una persona sola únicamente podría querer lo inferior a sí. El dar y el aceptar se reclaman, y en Dios son del mismo nive ${ }^{17}$. No ama quien no se entrega, pero no se entrega quien no acepta la entrega ${ }^{18}$. De aquí deriva que quien más ama sea capaz de donar lo superior: el ser, por eso se comprende que Tomás de Aquino (De Potentia, q.3, a.4) describa la creación como 'donatio essendi' Por contraste con lo indicado, se puede advertir la reducción de la concepción de algunos pensadores recientes sobre el amor, pues lo han considerado como un 'acto de la voluntad'. Con todo, la visión reductiva de la voluntad es todavía más patente en algún pensador moderno -Kant, por ejemplo-, quien declara que la voluntad es posición de sí. Por eso tal voluntad no es amorosa. Pero en el amor hay que rechazar el solipsismo y, por ende, el monismo ${ }^{19}$.

17 Un buen estudio de estas dimensiones se encuentra en Piá Tarazona, 2001.

18 Nótese que si esto se traduce en relaciones amorosas humano-divinas, hay que afirmar que no ama la persona humana que no se entrega a Dios, pero no se entrega a Dios quien no acepta su entrega, pues él se ha entregado primero. La iniciativa en el amor entre el hombre y Dios siempre es divina: «él nos ha amado primero» $(1 J n .4,21)$. 19 «El monismo, la teoría de que todo es uno o de que uno es todo, no se puede mantener si se tiene en cuenta el ser personal. Una única persona, un amar sin 
Como es sabido, la tradición medieval ha buscado la 'imagen divina' en la inteligencia y en la voluntad humanas (por ejemplo, Agustín de Hipona o Tomás de Aquino). De la primera facultad esa tradición ha dicho que la dualidad 'acto de conocer-objeto conocido' se parece a la relación Padre-Hijo (por eso se llama al Hijo Logos, Verbo, Palabra), mientras que ha indicado de la voluntad, que, como ésta potencia al querer no forma un objeto, se parece más al Espíritu Santo (de ahí su denominación de Amor o Don). Con todo, se trata una imagen que se toma de la esencia humana, porque ambas potencias forman parte de dicha dimensión del hombre. Sin embargo, si la imagen se toma del acto de ser personal humano, será mucho más fidedigna de la realidad pluripersonal divina. Como el amor personal forma parte del acto de ser —es lo superior de él一, las dimensiones del amor personal serán la mejor imagen del ser divino. Según esto, por lo pronto, no se pueden atribuir a Dios versiones rebajadas del amor que supongan deseo, tendencia, en rigor, potencialidad, porque Dios es acto. Tampoco hay que atribuir a Dios el querer de un acto que sea operación inmanente, pues es claro que ésta no es acto de ser. De manera que, en sentido estricto, sólo el amor, tomado como acto de ser, es atribuible al ser divino.

En las personas divinas no cabe hablar de superioridad e inferioridad $^{20}$, porque en ese caso la persona inferior no sería Dios, ya que en el ser divino no hay distinción real según jerarquía, sino sólo según pluralidad de personas. Sin embargo, si en nosotros el aceptar es superior al dar, somos más parecidos al Hijo; también porque en nosotros es más radical la filiación, que la paternidad. No somos originarios sino originados. Por tanto, no podemos inventar nuestro propio sentido personal, sino descubrirlo, aceptarlo, seguirlo. Por eso, «la persona humana se asimila al Hijo de Dios, al Verbo Divino, a la segunda Persona de la Santísima Trinidad. Porque, digámosolo así, dando un salto a la Teología Trinitaria, el dar corresponde al Padre, y el

correspondencia, no pasa de ser una veleidad que sólo se mantiene saliéndose de la realidad con ilusiones y fantasías. Lo más alto que existe es la persona - dignior in natura $\gg$ (Polo, 1999: 66). Más adelante añade: «la persona humana es incompatible con el monismo, y que la co-existencia no es de índole reflexiva. Ello se confirma al exponer la estructura donal. La persona humana es un don creado que se acepta como un dar destinado a ser aceptado. Esta segunda aceptación transciende sin más a la persona humana» (Polo, 1999: 221). Y en otra obra indica: «El amor es un trascendental que invita al encuentro de la otra persona. En definitiva, la soledad de la persona ha de ser superada según el encuentro con otra persona, pues una existencia monádica, solitaria, sería, para la persona, la desgracia pura» (Polo, Epistemología, creación y divinidad, pro manuscripto, 129).

20 «Et in hac Trinitate nihil prius aut posterius, nihil maius aut minus: sed totae tres personae coeternae sibi sunt et coequales» (Symbolun Athanasianum, 24). 
aceptar al Hijo. El Hijo es el amén. El amen es decir sí al dar» (Polo, Conversaciones en Torreblanca, pro manuscripto, 8$)^{21}$.

\section{E1 amor pluripersonal divino (II): el Don}

Aceptar y dar son dos dimensiones trascendentales o íntimas del amor personal humano. Pero el dar y el aceptar reclaman el don. Sin embargo, a este nivel no existe una tercera dimensión amorosa en la persona humana, pues se da en otros niveles inferiores del hombre. Esto significa que el amor íntimo del acto de ser personal se manifiesta necesariamente en la esencia y naturaleza humanas. Por eso, nativamente, se puede considerar tanto a la esencia como a la naturaleza corpórea humana como dones. En efecto, el yo, la inteligencia y la voluntad conforman la esencia humana y nativamente son dones. Por su parte, el cuerpo y todas sus facultades orgánicas también son originariamente un don. No obstante, el amor personal humano hace crecer la esencia y la naturaleza humana otorgándoles nuevos dones. La naturaleza corpórea crece hasta cierto límite, el cual termina ordinariamente en edad temprana tras la juventud y a partir de ese momento tiende a la baja hasta su pérdida completa con la muerte. En cambio, la esencia - por carecer de límites corpóreos- es susceptible de crecer irrestrictamente. En efecto, los hábitos intelectuales son el crecimiento de la inteligencia humana, y las virtudes el de la voluntad, y ambas perfecciones son susceptibles de crecimiento irrestricto. Por su parte, el yo también puede crecer personalizándose cada vez más.

En suma, «si se tiene en cuenta que el tercer miembro de la estructura donal - el don, el amor- no es un trascendental de la persona humana (del acto de ser), se concluye que es esencial (de la esencia humana); puesto que la estructura donal no puede quedar incompleta» (Polo, 2003: $23)^{22}$. Esto indica que el amor trascendental, como reza el refrán castizo

21 Y añade: «En el caso del hombre, como no es personalmente trinitario, el amor personal es dar y aceptar, antes aceptar y después dar, porque primero hay que aceptar el don divino, y por eso el hombre se asimila al Hijo» (Polo, Conversaciones en Torreblanca, pro manuscripto, 8). En la persona humana el dar es segundo respecto del aceptar y está en función del aceptar: «el amar se destina a la aceptación, y sin ella no nace... La destinación del amar al aceptar es la asimilación creatural al Hijo de Dios. Al ser inabarcable la aceptación divina, ésta constituye en antropología la guía hacia lo insondable» (Polo, Epistemología, creación y divinidad, pro manuscripto, 178).

22 Previamente había indicado: «al hablar de la estructura donal, el amar —el dar- y el aceptar son trascendentales personales. En cambio, el amor —el don- en el hombre no es trascendental sino esencial, y equivale al carácter constituyente de lo voluntario» (Polo, 1999: 238). 
'obras son amores y no buenas razones', se traduce en obras. La primera 'obra' del amor personal es la maduración o personalización del 'yo'; la segunda, la activación progresiva - habitual- de la inteligencia; la tercera, el perfeccionamiento virtuoso de la voluntad ${ }^{23}$. Contando con esas 'obras', que son 'inmanentes', el hombre es capaz de aportar dones 'transitivos' a las facultades humanas con soporte orgánico y, con ellas, puede añadir dones externos de todo tipo -lingüísticos, laborales, económicos, etc.-

Como es claro, en la persona humana los dones que ofrece son inferiores a ella. Si el don nace de la persona oferente, él tiene que tener como aceptante a una persona distinta. Las demás personas humanas pueden aceptar muchos de nuestros dones, pero quien puede aceptarlos todos y de modo completo sólo es Dios. Por tanto, en últimas, es a él a quien hay que ofrecer nuestras obras: «la persona humana desciende a su esencia... en cuanto que constituye lo voluntario, es oferente. Se trata de un don que suplica la aceptación divina». También es él quien eleva esos dones por encima del nivel personal humano.

Ahora bien, en el caso del amor pluripersonal divino, no se puede mantener la inferioridad del don. En Dios sólo cabe mantenerla respecto de lo creado. Por tanto, el amor o don en Dios no puede faltar ni ser inferior a su Dar y a su Aceptar, sino del mismo nivel: «en Dios el amor como don no se puede entender como perfección distinta de su amar radical. En cambio, en el hombre, la voluntad como potencia pasiva pura o relación trascendental con el bien permite la constitución de la dimensión donal del amar» (Polo, 2003: 127). La teología de la fe nos ayuda a comprenderlo, pues enseña que el Espíritu Santo no es la primera persona, ni la segunda, sino la tercera, pero ni posterior ni inferior a las precedentes.

Si indagamos en el amor divino teniendo en cuenta lo que precede y la revelación cristiana, se advierte que el Espíritu Santo no puede ser un segundo Hijo, porque de serlo la distinción entre el Dar y el Aceptar divino no sería real ni estaría al mismo nivel. En efecto, precisamente porque el Hijo es la perfecta aceptación del Padre, el Espíritu Santo no puede ser otro aceptar, porque eso implicaría que el primer aceptar no es perfecto o divino. Pero sí puede ser el don perfecto. Sin dar no es posible el aceptar, y a la inversa, pero sin éstos no es posible el don. A la par, el don reclama el dar y el aceptar porque los vincula. Entre los hombres el don, las obras, siempre son menores que el dar y el aceptar

23 «Como la persona humana es creada, para que el amar personal adquiera carácter de don, son precisos los actos voluntarios... Dicha aportación es imprescindible para que la estructura donal de la persona sea completada por el amor» (Polo, 2003: 127). 
(salvo en el caso de que concurra Dios en la donación: la unión matrimonial que engendra al hijo, el cual es una nueva persona no inferior a los padres).

Pero en Dios, si se da el dar y el aceptar, y son del mismo nivel, el don tiene que ser tercero y distinto del dar y del aceptar y de su mismo nivel: «la aceptación en Dios es el Hijo. El Hijo es el amén, el decir que sí a la donación paterna y, por eso, es posible el don, el Espíritu Santo. Me parece que es el modo de mostrar que el Filioque es cierto; que los que dicen los ortodoxos griegos que el Espíritu Santo procede del Padre exclusivamente no es posible» (Polo, Conversaciones en Torreblanca, pro manuscripto, 184).

\section{Conclusiones}

Las podemos sintetizar en las siguientes nueve tesis:

1. La persona humana está abierta amorosamente al mundo, pero no por el mundo, sino porque éste es un don para que la persona humana lo acepte, y porque ésta le puede añadir dones para que los acepten las demás personas.

2. La persona humana es susceptible de dos tipos de correcto amor de sí: a) uno inferior: amar su yo manifestando en él su sentido personal propio; b) otro superior: amarse como amante precisamente por saberse amado. En ambas se excluye la reflexión.

3. La persona humana está abierta amorosamente a las demás personas creadas. Ese amor es personal si ama a las personas, no a las cualidades de las personas (lo cual distingue el amor de la amistad).

4. La persona humana está, desde el origen, abierta amorosa y libremente al amor divino. Tal amor personal humano es constitutivamente creciente, porque sólo el ser divino puede aceptar enteramente el amor personal humano.

5. El amor personal humano puede ser elevado por el don sobrenatural divino de la caridad, que añade al amor natural la coexistencia amorosa íntima y libre entre las personas divinas y la persona humana.

6. El amor personal divino respecto del hombre no radica en su voluntad, puesto que Dios no es 'potencia', sino en su 'acto de ser' y, por tanto, el amor divino al hombre no es necesario sino libre.

7. La misericordia divina, fruto del amor divino a la persona humana, es un afecto divino. Se distingue de la compasión, porque ésta mira siempre a lo inferior como tal, mientras que la primera eleva a la persona humana. 
8. En el amor divino no cabe un dar sin un aceptar como personas distintas. El dar se asimila al Padre, mientras que el aceptar al Hijo. Ambos son del mismo nivel.

9. El dar y el aceptar divinos requieren del don, que sea del mismo nivel que aquéllos y sea persona distinta. El Espíritu Santo se asimila al don, y no puede darse sin el dar y el aceptar. Por eso, no es un segundo aceptar.

\section{REFERENCIAS}

-PiÁ Tarazona, S. (2001). El hombre como ser dual. Pamplona: Eunsa.

-POLO, L. (1993). Presente y futuro del hombre. Madrid: Rialp.

-POLO, L. (1995). Introducción a la filosofía. Pamplona: Eunsa.

-POLO, L. (1996a). La persona bumana y su crecimiento. Pamplona: Eunsa.

-POLO, L. (1996b). Sobre la existencia cristiana. Pamplona: Eunsa.

-POLO, L. (1996c). Ética: hacia una versión moderna de temas clásicos. Madrid: Aedos.

-POLO, L. (1997). El profesor universitario. Bogotá: Universidad de La Sabana.

-POLO, L. (1999). Antropología trascendental, I, Pamplona: Eunsa.

-POLO, L. (2003). Antropología trascendental, II, Pamplona: Eunsa.

-POLO, L. (2005). Nietzsche como pensador de dualidades. Pamplona: Eunsa.

-POLO, L. (2007a). Ayudar a crecer. Cuestiones de filosofía de la educación. Pamplona: Eunsa-Astrolabio.

-POLO, L. (2007b). Persona y libertad. Pamplona: Eunsa.

-POLO, L. (2008). El hombre en la historia. Cuadernos de Anuario Filosófico, Serie Universitaria, $\mathrm{n}^{\circ}$ 207, Pamplona: Servicio de Publicaciones de la Universidad de Navarra.

-PolO, L. (2009). Lecciones de psicología clásica. Pamplona: Eunsa.

-POLO, L. (2011). La esencia del hombre. Pamplona: Eunsa.

-POLO, L. (2012a). Filosofía y economía. Pamplona: Eunsa.

-POLO, L. (2012b). Estudios de filosofía moderna y contemporánea. Pamplona: Eunsa.

Sumario: Planteamiento; 1. La apertura amorosa al mundo; 2. Amor de sí positivo y negativo; 3 . El amor personal a los demás; 4. La apertura amorosa a Dios; 5. La elevación de la apertura amorosa a Dios; 6. El amor personal divino respecto del hombre; 7. La misericordia divina; 8 . El amor pluripersonal divino (I): el Dar y el Aceptar; 9. El amor pluripersonal divino (II): el Don; Conclusiones; Referencias. 